\title{
CREATING A STANDARD OF PRACTICE FOR LICENSE ALTERNATIVES
}

\author{
Christina M. Geuther(cguether@ksu.edu) Electronic Resources Librarian, Kansas State \\ University Libraries
}

Mira E. Greene (mirage@ksu.edu) Head, Content Development \& Acquisitions, Kansas State University Libraries

\begin{abstract}
A gap exists in library literature for license alternative practices. Although licensing processes are a new concept, there is enough knowledge of best practices that will apply to alternatives. Much of the life cycle of electronic resources with and without licenses remains the same; therefore, a workflow can be framed for alternatives. Kansas State University created a standard workflow for managing license alternatives in its management systems Verde and Alma. We based this standard on the differences between licenses and their conventional alternatives, the NISO Shared Electronic Resource Understanding, as well as terms of use without registered or signed agreement. Aspects of this presentation will also apply to institutions without electronic resource management (ERM) systems. After considering the acquisition and review practices of license alternatives, a discussion of interlibrary loan as well as enforcing terms in the patron community will be offered. Interlibrary loan staff will easily interpret their procedures of Fair Use based on documentation in the ERM.
\end{abstract}

\section{WHY DOCUMENT ALTERNATIVES?}

License alternatives are handled differently in the workflow process. Unlike the conventional negotiation process when the licensor provides a standard license amendment appropriate for the electronic resource, the licensee reviews the terms and requests modifications and/or supplies possible addendums which is reviewed by the licensor for new language and provides feedback with a modified document if the requests are accepted, and the licensee reviews the modified license to decide to accept and sign, the license alternatives are not negotiable. While libraries have a standard of best practices for licensing with policies and checklists, license alternatives are not as easy to determine and document. However, Interlibrary Loan department and Fair Use needs anticipate direction on electronic resources obtained by libraries. Therefore, it is imperative to document and copy the alternative license at time of purchase.

\section{SERU: A SHARED ELECTRONIC RESOURCE UNDERSTANDING}

A Shared Electronic Resource Understanding (SERU) was adopted as a NISO Best Practice in 2008. At that time the focus was on electronic journals; however, it has expanded into e-books. SERU offers an alternative for publishers and libraries to license agreements. The SERU statement expresses commonly shared understandings of the publisher, the subscribing institution, and authorized users on the nature of the content, user of material, online performance, and archiving and perpetual use. Use of SERU gives benefits to both publishers and libraries by removing the overhead of license negotiation. By registering for SERU, the publisher and institution have a cooperative and collaborative relationship with a mutual understanding between both parties.

\section{TERMS OF USE WITH OR WITHOUT A LICENSE}


Terms of use may appear outside of a license or the Shared E-Resource Understanding agreement. Some vendors list authorized users, interlibrary loan, and other terms of use on their website in a section for librarians; or it may be even more hidden in a Frequently Asked Question section. Nevertheless, these terms of use should be treated with the same weight as a license agreement. They should be documented in the electronic resource system or modules to give collection development librarians and interlibrary loan staff direction.

\section{K-STATE LIBRARIES' PROCESS FOR LICENSE ALTERNATIVES}

Kansas State University has two standardized workflows for processing license and license alternatives in the electronic resource management system. They are similar in structure and outcome. For licensing, there are five major steps: Acquire first draft of license from vendor and the business terms requested by Content Development Librarians; Negotiation of license terms and addenda; Submit to local signatories, vendor, and await countersignature; Documentation of license terms and file management; and Interpret license upon staff request. For the license alternative workflow, there are again five major steps: Contact vendor for most recent terms of use and to ensure there is not a license that can be negotiated; Consider terms of use and whether the needs of the Library will be met; Register for SERU when applicable; Documentation of terms of use and file management; and Interpret SERU or terms of use upon staff request. The difference between the two workflows is that negotiation is not taking place for the license alternatives, although our workflow establishes the same procedures for checking against policy and a checklist with the same concerns for all documents considered.

First, the electronic resources librarian contacts the vendor for most recent terms of use and to ensure there is not a license that can be negotiated. The vendor's website may or may not have all of the information you need to make a collection development decision. Terms of use may be listed, but it is possible that there could be further documentation from contacting a vendor. If the vendor does not have terms currently in place, try suggesting the Shared E-Resource Understanding and proceed with Step 2. If there is a license that can be negotiated, use a licensing workflow. Finally, if there are terms of use only, make sure they are the most recent and check how regularly they may be updated. There may be other issues present if your state has requirements of purchases and contractual obligations. For example, in Kansas we have a required state form for purchases over a certain amount, and that must be incorporated in a license.

Second, the librarian must consider terms of use and whether the needs of the library will be met. Review the terms of agreement as carefully as when negotiating a license. Terms of agreement outside of a license cannot be negotiated, so contact the vendor and document areas needing clarification. Apply the same checklist and red flags as licenses. Checklists are quick visual guides for navigating sometimes complicated terms. A checklist may be used in the creation of a licensing and license alternative policy as well as part of the process of reviewing the terms. Policy enforces consistency in reviewing terms and agreements, and facilitates understanding among library staff assessing collection development once a resource is approved. One of the red flags Kansas State University considers is indemnification. Indemnification can go two ways: by the Library or the vendor. Watch for language calling for the Library to indemnify the vendor, because it carries the obligation to 
legally defend or pay legal fees to defend the other party from a third party's claims that may result from the agreement. Also look for the specified venue where legal action to resolve a dispute should take place, especially if your institution is restricted by law to its own state. What are the user restrictions? At Kansas State University, we have to consider our collections' purpose as a land grant university. We have to ensure walk-ins, who are unaffiliated persons using an electronic resource on-site.

Third, the library will register for SERU when applicable. Confirm the use of SERU with the vendor. This may be the first time a vendor has used SERU or they may have little experience, so check the NISO registry for SERU participants. Your university should be listed with up-todate contact information. Then link the SERU license record to the appropriate electronic resource in the electronic resource management system or unified resource management system. At Kansas State University, we keep one SERU license record to update. We do not modify the terms of SERU to call for separate records for each electronic resource. This procedure was changed when we migrated from Ex Libris Verde to Alma resource management.

\section{RECORDING IN THE ELECTRONIC RESOURCE MANAGEMENT SYSTEM}

Documentation of terms of use and file management much be completed in a timely manner. When working with the license interface of an electronic resource management system, the text input fields for terms are laid out in a particular order that may not be reflected in the terms of use needing to be documented. Answering each field requires working back and forth between the sections of a document. Accordingly, it is easier to first make a template of the ERM license interface in Microsoft Word. Reread the Word document against the SERU or terms of use. Then copy the information over to the license form of the ERM/URM. Attach a copy of the terms of agreement to the form. Make a screen capture of the terms posted on the vendor website at the time of agreement. Email communication can be used in legal exchange, so at Kansas State University we maintain any vendor emails with clarification of terms in a backed up hard drive. We have a practice of maintaining those licensing and license alternative exchanges for at least five years, although we have used even older recorded emails for negotiations.

\section{OUTCOMES: ENFORCING TERMS, ILL, AND FAIR USE}

At Kansas State University, the three most common reasons to interpret license alternatives for staff are: public services refers a patron who wants to use an electronic resource in a manner that may be reflected in the terms of use; Fair Use implications are unclear; and the management system license interface does not have enough information to answer a question. In our case, the Electronic Resources Librarian does not have much contact with patrons and works behind the scenes in technical services. First, library staff contacts the Electronic Resources Librarian to interpret the terms of agreement. Then the Electronic Resources Librarian looks through documented emails in the backed up licensing hard drive and the most current agreement in the management system to identify whether the staff's terms of use question has an established answer. If the documentation shows an unclear answer, the Electronic Resources Librarian becomes the main contact for communication over the matter with the vendor licensing representative. The issue is treated in the best interest of the university, whether reading the gray area at an advantage or deciding to be conservative based on most practices (such as avoiding systematic downloading). If, on the other hand, when the Electronic Resources Librarian looked 
through the documentation in the licensing folder and management system there is a clear answer, she cites the terms of agreement by email exchange with the staff and appropriate patron.

Interlibrary Loan uses the license information documented in the ERM/URM to determine permissions. The license module in Alma was configured to have the ILL information in the uppermost portion of the interface. The process of documenting the terms of use and SERU gives ILL and consistent workflow and the ability to make these determinations without intervention of the Electronic Resources Librarian. They can quickly decide whether the permissions allow sharing of the material.

\section{CONCLUSION}

Kansas State University has found that developing a standard of documenting license alternatives has cut staff time answering questions on terms, interlibrary loan, and Fair Use. By developing a workflow for documentation, records are streamlined and consistent. The record only has to be updated at the time of purchase unless a question on enforcing terms is requested. Whether a library uses an electronic resource management or not, there is a standard and checklist that will make license alternatives manageable for library staff.

\section{REFERENCES}

Albitz, B. (2008). Licensing and managing electronic resources. Oxford: Chandos.

Bosch, S. (2005). Guide to licensing and acquiring electronic information. Lanham, Md: Scarecrow Press.

Collins, M. (2007). SERU: An Alternative to Licensing-An Interview with Selden Durgom Lamoureux. Serials Review, 33(2), 122-128.

Eschenfelder, K. R. Tsai, T.I., Zhu, X., \& Stewart, B. (2013). How Institutionalized Are Model License Use Terms? An Analysis of E-Journal License Use Rights Clauses from 2000 to 2009. College \& Research Libraries, 74(4), 326-355.

Lipinski, T. A. (2013). The librarian's legal companion for licensing information resources and services. Chicago: Neal-Schuman, An imprint of the American Library Association.

NISO RP-7-2012, SERU: A Shared Electronic Resource Understanding - RP-7-2012_SERU.pdf. (n.d.). Retrieved from http://www.niso.org/publications/rp/RP-7-2012_SERU.pdf

Rupp-Serrano, K. (2005). Licensing in libraries: practical and ethical aspects. Binghamton, NY: Haworth Information Press. 